\section{A comparison of fentanyl, esmolol, and their combination for blunting the haemo- dynamic responses during rapid-sequence induction}

K. Sam Chung MD, Raymond S. Sinatra MD PhD, Jonathan D. Halevy MD, Darcy Paige RN, David G. Silverman MD
The purpose of this randomized, double-blind study was to compare the ability of a combination of fentanyl and esmolol to blunt the haemodynamic effects of intubation with that of either agent alone. Patients received fentanyl or saline four minutes before, and esmolol or saline two minutes before rapid-sequence induction of anaesthesia. The $F_{2}$ group $(n=24)$ received fentanyl $2 \mu \mathrm{g} \cdot \mathrm{kg}^{-1}$, the $E_{2}$ group $(n=24)$ received esmolol 2 $\mathrm{mg} \cdot \mathrm{kg}^{-1}$, the $F_{2} / E_{2}$ group $(n=25)$ received a combination of fentanyl $2 \mu \mathrm{g} \cdot \mathrm{kg}^{-1}$ and esmolol $2 \mathrm{mg} \cdot \mathrm{kg}^{-1}$, and the $F_{5}$ group ( $\mathrm{n}$ = 26) received fentanyl $5 \mu \mathrm{g} \cdot \mathrm{kg}^{-1}$. Following tracheal intubation, the maximum percent change from baseline heart rate was less in the $F_{2} / E_{2}$ and $F_{5}$ groups (12\% and $16 \%$ respectively) than in the $E_{2}$ group $(34 \%)(P<0.05)$. The maximum percent changes from baseline systolic blood pressure in the $F_{2} / E_{2}$ and $F_{5}$ groups (15\% and $6 \%$ respectively) were less than in the $F_{2}$ and $E_{2}$ groups (24\% and $33 \%$ respectively) $(P<0.05)$. The combination

\section{Key words}

ANALGESICS: fentanyl;

INTUBATION, TRACHEAL: complications;

SYMPATHETIC NERVOUS SYSTEM: beta receptor antagonist, esmolol.

From the Department of Anesthesiology, Yale University School of Medicine, 333 Cedar Street, New Haven, CT 06510.

Address correspondence to: Dr. K. Sam Chung, Department of Anesthesiology, Yale University School of Medicine, 333 Cedar Street, New Haven, CT 06510.

Presented at the Annual Meeting of the American Society of Anesthesiologists, San Francisco, CA, October 26-30, 1991.

Supported in part by a research grant from DuPont Pharmaceuticals, U.S.A.

Accepted for publication May 12, 1992. of a low dose of fentanyl and esmolol provides an alternative to a higher dose of fentanyl for blunting the haemodynamic responses to laryngoscopy and tracheal intubation during rapidsequence induction in healthy patients.

Cette étude randomisée, à double insu, compare la capacité de blocage de la réponse hémodynamique à l'intubation de l'association fentany//esmolol avec celle des deux agents utilisés séparément. Les patients reçoivent soit du fentanyl ou du soluté physiologique, soit de l'esmolol ou du soluté physiologique, respectivement à quatre minutes et à deux minutes de l'induction d'une anesthésie à séquence rapide. Le groupe $F_{2}(n=24)$ reçoit fentanyl $2 \mu \mathrm{g} \cdot \mathrm{kg}^{-1}$, le groupe $E_{2}(n=24)$ reçoit esmolol $2 \mathrm{mg} \cdot \mathrm{kg}^{-1}$, le groupe $F_{2} / E_{2}(n=25)$ reçoit une association de $2 \mu \mathrm{g} \cdot \mathrm{kg}^{-1}$ de fentanyl et d'esmolol $2 \mathrm{mg} \cdot \mathrm{kg}^{-1}$ et le groupe $F_{5}$ ( $n=26$ ) reçoit fentanyl $5 \mu \mathrm{g} \cdot \mathrm{kg}^{-1}$. Après l'intubation endotrachéale, le pourcentage maximal de variation de la fréquence cardiaque initiale est moindre pour les groupes $F_{2} / E_{2}$ et $F_{5}$ (respectivement $15 \%$ et $16 \%$ ) que pour le groupe $E_{2}(34 \%)$ $(P<0,05)$. Le pourcentage maximal de variation de la tension systolique initiale pour les groupes $F_{2} / E_{2}$ et $F_{5}$ (respectivement $15 \%$ et $6 \%$ ) est moindre que pour les groupes $F_{2}$ et $E_{2}$ (respectivement $24 \%$ et $33 \%$ ) $(P<0,05)$. L'association d'une faible dose de fentanyl et d'esmolol constitue une alternative valable aux doses élevées de fentanyl pour atténuer les effets hémodynamiques de la laryngoscopie directe et de l'intubation endotrachéale lors de l'induction à séquence rapide de l'anesthésie chez des sujets en bonne santé.

Anaesthetists have employed a multitude of regimens to block the afferent and/or efferent limbs responsible for the haemodynamic responses to intubation of the trachea. Fentanyl in doses greater than or equal to $5 \mu \mathrm{g} \cdot \mathrm{kg}^{-1}$ has been reported to be effective. ${ }^{1,2}$ However, such doses of fentanyl may lead to excessive sedation, apnoea and chest wall rigidity preoperatively, and to nausea, vomiting and 
respiratory depression postoperatively. ${ }^{3-5}$ While an agent such as esmolol avoids these complications, it has variable effectiveness in the recommended doses (100-200 mg). ${ }^{6-9}$ We postulated that, by both modulating nociceptive input and blunting peripheral adrenergic effects, a combination of fentanyl and esmolol might prove to be more efficacious than either agent alone. The potential benefits of such combination therapy were suggested by previous investigations. ${ }^{10,11}$ This randomized, double-blinded study was designed to compare a combination of fentanyl 2 $\mu \mathrm{g} \cdot \mathrm{kg}^{-1}$ and esmolol $2 \mathrm{mg} \cdot \mathrm{kg}^{-1}$ with a regimen of fentanyl $2 \mu \mathrm{g} \cdot \mathrm{kg}^{-1}$ alone, fentanyl $5 \mu \mathrm{g} \cdot \mathrm{kg}^{-1}$ alone, or esmolol $2 \mathrm{mg} \cdot \mathrm{kg}^{-1}$ alone.

\section{Methods}

Following approval of the institutional Human Investigation Committee, informed written consent was obtained from 102 patients scheduled for elective surgery of longer than one hour in duration. Exclusion criteria were ASA physical status III-V, age $<21$ or $>65 \mathrm{yr}$, weight $<50$ or $>100 \mathrm{~kg}$, atrial or ventricular arrhythmias, second or third degree A-V conduction block, hypertension, congestive heart failure, bronchial asthma, chronic narcotic use, or beta-adrenergic antagonist therapy. Patients were randomly allocated to one of four treatment groups in a doubleblind fashion: the $F_{2}$ group received fentanyl $2 \mu \mathrm{g} \cdot \mathrm{kg}^{-1}$, the $E_{2}$ group received esmolol $2 \mathrm{mg} \cdot \mathrm{kg}^{-1}$, the $F_{2} / E_{2}$ group received a combination of fentanyl $2 \mu \mathrm{g} \cdot \mathrm{kg}^{-1}$ and esmolol $2 \mathrm{mg} \cdot \mathrm{kg}^{-1}$, and the $F_{5}$ group received fentanyl $5 \mu \mathrm{g} \cdot \mathrm{kg}^{-1}$. Each regimen consisted of two syringes which were prepared by an investigational pharmacist. Syringe A contained $10 \mathrm{ml}$ of either saline, fentanyl $2 \mu \mathrm{g} \cdot \mathrm{kg}^{-1}$ or fentanyl $5 \mu \mathrm{g}^{-1} \cdot \mathrm{kg}^{-1}$; syringe $\mathrm{B}$ contained $20 \mathrm{ml}$ of saline or esmolol $2 \mathrm{mg} \cdot \mathrm{kg}^{-1}$. A benzodiazepine premedication (midazolam $0.02-0.04 \mathrm{mg} \cdot \mathrm{kg}^{-1}$ im or diazepam 0.15 $\mathrm{mg} \cdot \mathrm{kg}^{-1} \mathrm{po}$ ) was administered at the discretion of the patient's anaesthesia care provider; the dose was not dictated by the study protocol so as to enable us to assess the four study groups in the context of routine care at our institution.

In the OR, baseline heart rate (HR) and blood pressure (BP) were obtained by automatic noninvasive brachial oscillometry and ECG (Lead II) after the patient was placed on the OR table. Such measurements were obtained at each event of the study protocol (Figure 1), and repeated at one-minute intervals until five minutes after tracheal intubation. At two-minute intervals during preoxygenation, the patient received the contents of syringe $A$, syringe $B$, and then an induction dose of thiopentone $\left(4 \mathrm{mg} \cdot \mathrm{kg}^{-1}\right)$ which was followed immediately by succinylcholine ( 1.5 $\mathrm{mg} \cdot \mathrm{kg}^{-1}$ ). One minute after the beginning of administration of the induction agent, laryngoscopy and intubation were performed. Then, mechanical ventilation with $100 \%$

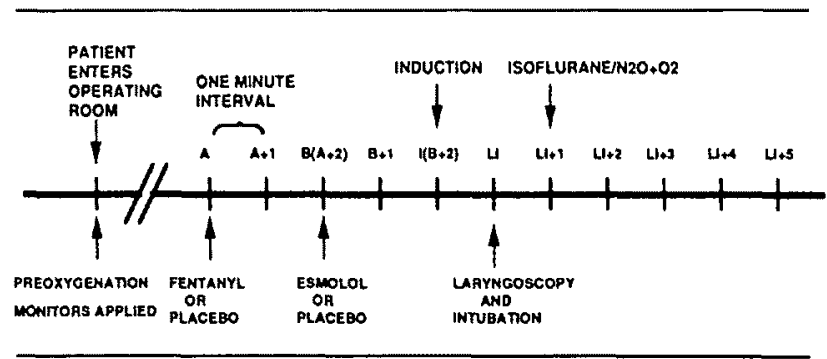

FIGURE 1 Time line of events and data collection points. Interval between successive vertical lines is one minute. $A$ and $B$ indicate times of injection for syringes $A$ and $B$, respectively. $I=$ induction; $L I=$ laryngoscopy and intubation.

oxygen was commenced to maintain end-tidal $\mathrm{CO}_{2}$ at 30-35 $\mathrm{mmHg}$. One minute after intubation, $1 \%$ isoflurane and $70 \% \mathrm{~N}_{2} \mathrm{O}$ were added and maintained during the remainder of the study period. Post-intubation hypertension (systolic BP $>160 \mathrm{mmHg}$ or $>20 \%$ above baseline) and tachycardia (HR $>100 \mathrm{bpm}$ ) were treated with incremental doses $(25 \mathrm{mg})$ of thiopentone.

Demographic data, the duration of laryngoscopy and intubation, and maximum percent changes in $H R$ and $B P$ during the five minutes following intubation were analyzed using analysis of variance (ANOVA). The HR and $B P$ at each time and changes in HR and BP from baseline were analyzed using ANOVA, repeated measures ANOVA, and Student-Newman-Keuls for multiple comparisons. Fisher's exact and chi-squared tests were used to compare the groups with respect to the proportion of patients with "pre-defined" extreme changes in HR and BP. When a difference in proportions was found among the groups, pairwise comparisons were done, and a Bonferroni adjustment was made for multiple comparisons. An alpha level of $5 \%(P<0.05)$ was used to establish statistical significance.

\section{Results}

Of the 102 patients enrolled, three did not complete the study: one in the $F_{2}$ group required multiple attempts at intubation, one in the $E_{2}$ group required awake tracheal intubation and a third withdrew from the study after consent was signed. Demographic data for the 99 remaining patients are presented in Table I. There were no differences among the groups with respect to sex, age, weight, height, ASA physical status, or premedication; nor were there differences among the groups with respect to the baseline HR and BP or duration of laryngoscopy and intubation (which averaged $27 \mathrm{sec}$ overall). Except for one case of apnoea requiring assisted ventilation before induction in the $F_{5}$ group, there were no other adverse events, i.e., severe bradycardia, hypotension, chest wall rigidity, or post-surgical respiratory depression. 
TABLE I Patient demographics data

\begin{tabular}{lcclc}
\hline & $\begin{array}{l}F_{2} \text { group } \\
(n=24)\end{array}$ & $\begin{array}{l}E_{2} \text { group } \\
(n=24)\end{array}$ & $\begin{array}{l}F_{2} / E_{2} \text { group } \\
(n=25)\end{array}$ & $\begin{array}{l}F_{5} \text { group } \\
(n=26)\end{array}$ \\
\hline Sex & & & & \\
- Male (n) & 3 & 3 & 4 & 8 \\
- Female $(n)$ & 21 & 21 & 21 & 18 \\
Age $(\mathrm{yr})^{\mathrm{a}}$ & $41 \pm 2$ & $42 \pm 2$ & $40 \pm 2$ & $39 \pm 2$ \\
Weight $(\mathrm{kg})^{\mathrm{a}}$ & $70 \pm 2$ & $65 \pm 2$ & $70 \pm 2$ & $69 \pm 2$ \\
Height $(\mathrm{cm})^{\mathrm{a}}$ & $165 \pm 2$ & $164 \pm 1$ & $163 \pm 2$ & $166 \pm 2$ \\
ASA Physical Status & & & & \\
- I $(n)$ & 12 & 12 & 15 & 14 \\
- Il $(n)$ & 12 & 12 & 10 & 12 \\
Premedication & & & & \\
- Yes $(n)$ & 19 & 20 & 22 & 21 \\
- No $(n)$ & 5 & 4 & 3 & 5 \\
\hline
\end{tabular}

${ }^{\mathrm{a}}$ Mean $\pm \mathrm{SD}$.

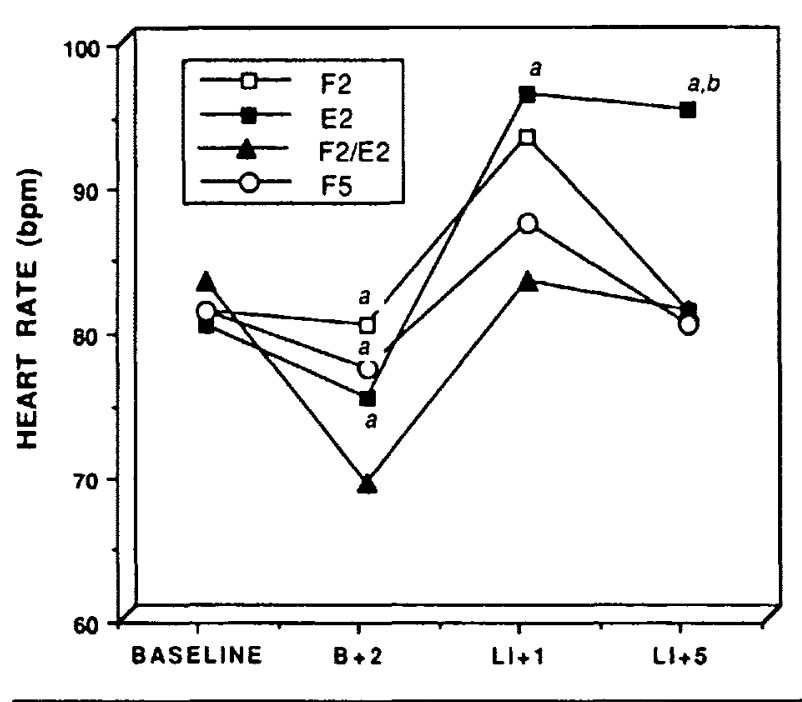

FIGURE 2 Heart rate (HR) responses at selected time points. The mean HR for each of the four groups is provided for the first assessment in operating room (baseline), two minutes after syringe $B(B+2)$, one minute after the onset of laryngoscopy $(\mathrm{LI}+1)$ and five minutes after the onset of laryngoscopy $(\mathrm{LI}+5), a=P<0.05$ vs $\mathrm{F}_{2} / \mathrm{E}_{2}$ group; $b$ $=P<0.05$ vs $\mathrm{F}_{5}$ group.

\section{Heart rate}

Patients in each group demonstrated a transient preinduction decrease in mean HR from baseline following the administration of fentanyl and/or esmolol (Figure 2). The greatest reduction was noted in the $\mathrm{F}_{2} / \mathrm{E}_{2}$ group $(P<0.05$ between $\mathrm{F}_{2} / \mathrm{E}_{2}$ and each of the other groups). One patient in the $E_{2}$ group and three in the $F_{2} / E_{2}$ group experienced a decrease in heart rate to less than $50 \mathrm{bpm}$ prior to induction; in all four patients, however, the HR increased to above baseline immediately after induction of general anaesthesia.

Following tracheal intubation, an increase in HR was noted in each group. The maximum percent change from baseline $H R$ was less in the $F_{2} / E_{2}$ and $F_{5}$ groups ( $12 \%$ and $16 \%$ respectively) than in the $\mathrm{E}_{2}$ group $(34 \%)(P<0.05)$, and also less than that in the $\mathrm{F}_{2}$ group (22\%) $(P=\mathrm{NS})$. A $\mathrm{HR}>100 \mathrm{bpm}$ was noted in 13 of 24 patients in the $E_{2}$ group, nine of 23 patients in $F_{2}$, three of 25 patients in $\mathrm{F}_{2} / \mathrm{E}_{2}$, and five of 26 patients in the $\mathrm{F}_{5}$ group (Table II, $P$ $<0.01$ for $E_{2}$ vs $F_{2} / E_{2}$ ).

\section{Blood pressure}

Following administration of fentanyl and/or esmolol, systolic blood pressure (SBP) tended to decline in each group ( $P=\mathrm{NS}$ ). Following intubation, however, SBP increased in all groups. The maximum percent change from baseline SBP in the $\mathrm{F}_{2} / \mathrm{E}_{2}$ and $\mathrm{F}_{5}$ groups (15\% and $6 \%$ respectively) was less than that in the $\mathrm{F}_{2}$ and $\mathrm{E}_{2}$ groups (24\% and 33\% respectively) $(P<0.05)$. It also was less in the $\mathrm{F}_{5}$ group than in the $\mathrm{F}_{2} / \mathrm{E}_{2}$ group $(P<0.05)$ (Figure 3 ). The proportion of patients with maximum SBP $>160$ mmHg in the $F_{2} / E_{2}$ and $F_{5}$ groups was less than one third of that noted in the $\mathrm{F}_{2}$ and $\mathrm{E}_{2}$ groups $(P<0.01$, Table II). The $\mathrm{F}_{5}$ group also experienced the highest incidence $(16 / 26)$ of a $20 \%$ or greater decrease in SBP $(P<0.01$ for $F_{5}$ vs $F_{2}$ and $E_{2}$ ). However, when only data obtained prior to the addition of isoflurane were analyzed, $5 / 26 \mathrm{~F}_{5}$ patients and $5 / 25 \mathrm{~F}_{2} / \mathrm{E}_{2}$ patients evidenced such a decrease. In general, diastolic blood pressure paralleled changes in SBP throughout the study period (Figure 4). A greater number of patients in the $F_{2}$ and $E_{2}$ groups required supplemental thiopentone for post-intubation hypertension and tachycardia (six in the $F_{2}$, six in the $E_{2}$, three in the $\mathrm{F}_{2} / \mathrm{E}_{2}$ and one in the $\mathrm{F}_{5}$ group); however, such intergroup differences were not statistically significant.

\section{Discussion}

Results obtained from the present investigation suggest 
TABLE II Incidence of extreme changes in HR and BP

\begin{tabular}{lllll}
\hline & $\begin{array}{l}F_{2} \text { group } \\
(n=24)\end{array}$ & $\begin{array}{l}E_{2} \text { group } \\
(n=24)\end{array}$ & $\begin{array}{l}F_{2} / E_{2} \text { group } \\
(n=25)\end{array}$ & $\begin{array}{l}F_{5} \text { group } \\
(n=26)\end{array}$ \\
\hline Minimum HR $<50 \mathrm{bpm}$ & 0 & 1 & 3 & 0 \\
Maximum HR $>100 \mathrm{bpm}$ & 9 & $13^{\mathrm{a}}$ & 3 & 5 \\
Maximum SBP $>160 \mathrm{mmHg}$ & $14^{\mathrm{a}, \mathrm{b}}$ & $15^{\mathrm{a}, \mathrm{b}}$ & 4 & 2 \\
\hline
\end{tabular}

$\mathrm{HR}=$ heart rate; $\mathrm{BP}=$ blood pressure; $\mathrm{SBP}=$ systolic blood pressure.

${ }^{\mathrm{A}} P<0.01$ vs $\mathrm{F}_{2} / \mathrm{E}_{2}$ group.

${ }^{b} P<0.01$ vs $F_{5}$ group.

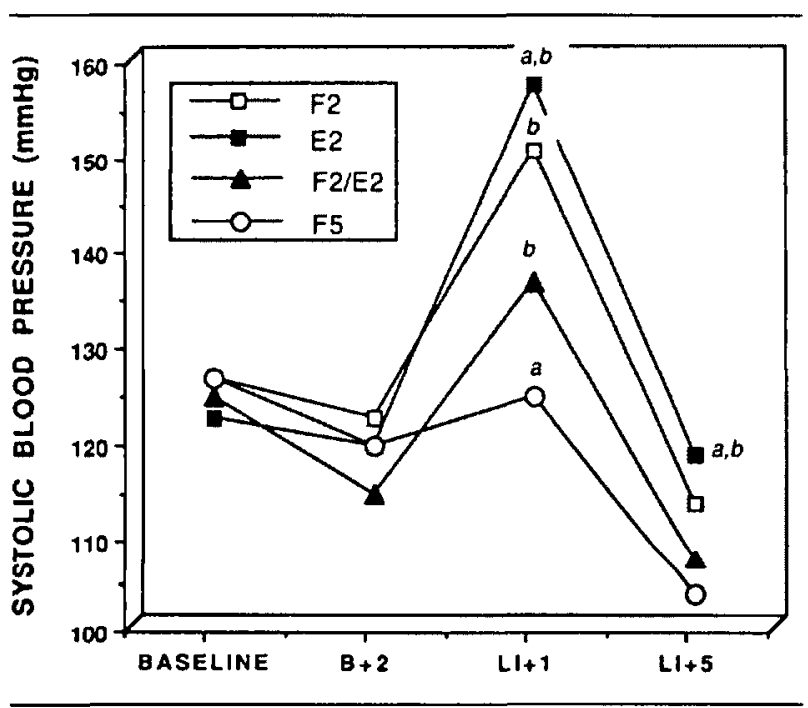

FIGURE 3 Systolic blood pressure (SBP) responses at selected time points. The mean SBP for each of the four groups is provided at baseline, two minutes after the syringe $B(B+2)$, one minute after the onset of laryngoscopy $(\mathrm{LI}+1)$ and five minutes after the onset of laryngoscopy $(\mathrm{LI}+5)$. $a=P<0.05$ vs $\mathrm{F}_{2} / \mathrm{E}_{2}$ group; $b=P<0.05$ vs $\mathrm{F}_{5}$ group.

that pretreatment with a combination of low-dose fentanyl and esmolol provides safe and effective suppression of the $\mathrm{HR}$ and BP responses to laryngoscopy and intubation in healthy patients. This combination may prove to be a suitable alternative when one seeks to avoid higher doses of opioids or esmolol. Only three patients receiving this combination experienced a peak HR above $100 \mathrm{bpm}$ following laryngoscopy and tracheal intubation. This group also evidenced a smaller change from baseline SBP and fewer patients with SBP $>160 \mathrm{mmHg}$ than did the groups receiving esmolol alone or low-dose fentanyl.

Esmolol $2 \mathrm{mg} \cdot \mathrm{kg}^{-1}$ administered alone did not consistently provide haemodynamic stability during laryngoscopy and intubation. Patients receiving esmolol alone experienced the highest degree of haemodynamic response to intubation. These findings are in general agreement with other investigators, ${ }^{6-9}$ who likewise noted that esmolol in doses of $100-200 \mathrm{mg}$ was only partially effective in blunting the haemodynamic responses. Furthermore, they were not markedly different from patients who received saline placebo in a similar setting. ${ }^{12}$ Although higher doses of esmolol might blunt both the HR and BP responses, they may be associated with myocardial depression. In this regard, Ebert et al. ${ }^{8}$ and Miller et al. ${ }^{10}$ reported reductions in cardiac index and ejection fraction following intubation when esmolol was administered in doses of 2.5-3 $\mathrm{mg} \cdot \mathrm{kg}^{-1}$.

Although fentanyl has been used to blunt the haemodynamic responses to intubation, ${ }^{1,2}$ moderate-to-high doses of fentanyl often are not given in a full-stomach rapidsequence setting for the fear of being unable to ventilate the lungs prior to induction or following a failed attempt at intubation. In the present study, one patient became apnoeic after receiving $5 \mu \mathrm{g} \cdot \mathrm{kg}^{-1}$ of fentanyl and required assisted ventilation before laryngoscopy. McClain et al. also reported apnoeic episodes in $4 / 7$ patients who received $3.2-6.5 \mu \mathrm{g} \cdot \mathrm{kg}^{-1}$ fentanyl. ${ }^{13}$ In addition, such

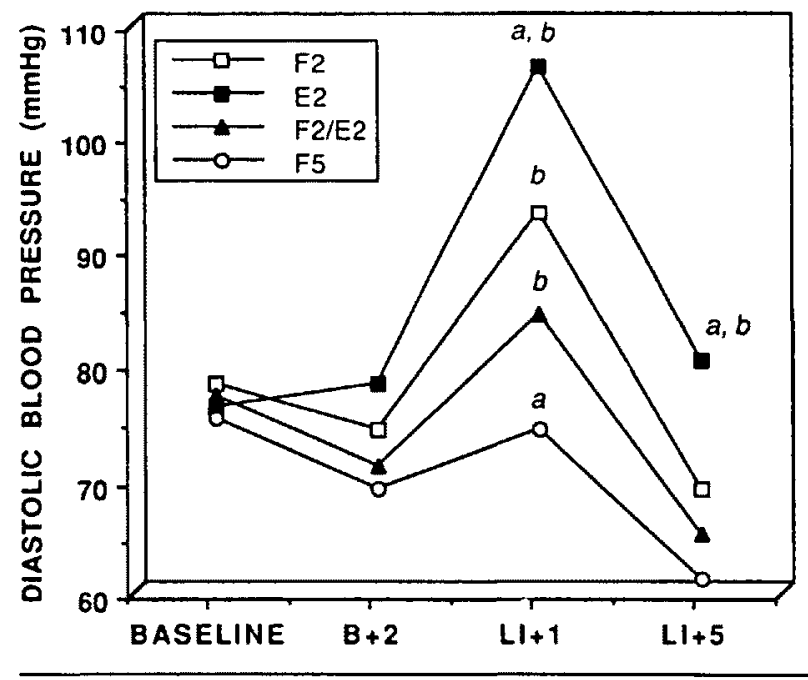

FIGURE 4 Diastolic blood pressure (DBP) responses at selected time points. The mean DBP for each of the four groups is provided at baseline, two minutes after syringe $B(B+2)$, one minute after the onset of laryngoscopy $(\mathrm{LI}+1)$ and five minutes after the onset of laryngoscopy (LI+5). $a=P<0.05$ vs $\mathrm{F}_{2} / \mathrm{E}_{2}$ group; $b=P<0.05$ vs $\mathrm{F}_{5}$ group. 
doses of fentanyl may lead to prolonged and recurrent ventilatory depression after relatively short surgical procedures lasting less than two hours. ${ }^{4,5,13}$ While this can be managed effectively with assisted ventilation, the present data suggest that the addition of esmolol allows the use of lower doses of respiratory depressants such as fentanyl and reduces the potential morbidity and costs associated with prolonged ventilatory assistance.

We postulated that fentanyl's modulation of nociceptive input and esmolol's blockade of adrenergic receptors should enable their combination to provide effective blunting of the response to intubation while minimizing the undesirable effects of larger doses of each agent alone. The potential benefit and safety of combination therapy were suggested by previous investigations; ${ }^{10,11}$ however, none of these was randomized with respect to whether or not patients received fentanyl. Cole ${ }^{11}$ reported that the addition of esmolol ( $100 \mathrm{or} 200 \mathrm{mg}$ ) to the $5 \mu \mathrm{g} \cdot \mathrm{kg}^{-1}$ dose of fentanyl that they administered to high-risk patients prior to induction did not affect the HR and BP responses to intubation (which already were blunted by the fentanyl). Their findings suggest the relative safety of combination therapy in that the incidence of bradycardia and hypotension associated with fentanyl/esmolol combination was similar to that observed following administration of fentanyl alone.

While we noted a decreased HR prior to induction of anaesthesia in the esmolol alone and combination groups, such changes were clinically insignificant; in each case, the HR increased to above baseline immediately after induction. Nevertheless, the central vagomimetic effect of fentany $1^{14}$ combined with the negative chronotropic effect of esmolol theoretically could result in severe bradycardia. Therefore, HR should be carefully monitored and appropriate treatments considered if severe, albeit typically transient, bradycardia is observed.

This study had some limitations. Although it recently has been reported that multiple regression analysis of pooled data from several institutions indicated that benzodiazepine premedication can have a moderating effect on the pressor response, ${ }^{15}$ we did not dictate the indications for, or the dose of, benzodiazepine. This was done so as to enable the assessment of the four study groups in the context of routine care at our institution. Of note, the number of patients who received premedication was similar in all four treatment groups. With respect to our study population, we did not randomize according to gender; this resulted in over-representation of females. Although the power of the present study was adequate to identify significant differences with respect to blood pressure, the power to identify a significant difference in maximum heart rate between $F_{2}$ and $E_{2} / F_{2}$ or $F_{2}$ and $F_{5}$ groups was low (30\%).
In summary, the combination of low-dose fentanyl (2 $\left.\mu \mathrm{g} \cdot \mathrm{kg}^{-1}\right)$ and esmolol $\left(2 \mathrm{mg} \cdot \mathrm{kg}^{-1}\right)$ is more effective than the same dose of either agent alone in blunting tachycardic and hypertensive responses to laryngoscopy and intubation following rapid-sequence induction. It is more effective in blunting the HR but was less effective in blunting the BP response than fentanyl $5 \mu \mathrm{g} \cdot \mathrm{kg}^{-1}$. It was associated with less hypotension than fentanyl $5 \mu \mathrm{g} \cdot \mathrm{kg}^{-1}$. The combination thus provides an alternative to a higher dose of fentanyl for blunting the haemodynamic responses to laryngoscopy and intubation during rapid-sequence induction in healthy patients. Follow-up studies evaluating the safety and efficacy in higher risk patients are warranted.

\section{Acknowledgements}

The authors wish to express gratitude to Medical Research International (Burlington, MA), and Theresa O'Connor, MPH for their statistical assistance and Jill Fuggi for her secretarial assistance.

\section{References}

1 Dahlgren $N$, Messeter $K$. Treatment of stress response to laryngoscopy and intubation with fentanyl. Anaesthesia 1981; 36: 1022-6.

2 Cork RL, Weiss JL, Hammeroff SR, Bentley J. Fentanyl preloading for rapid sequence induction of anesthesia. Anesth Analg 1984; 63: 60-4.

3 Harper M, Hickey RF, Cromwell TH, Linwood S. The magnitude and duration of respiratory depression produced by fentanyl and fentanyl plus droperidol in man. $\mathrm{J}$ Pharmacol Exp Ther 1976; 199: 464-8.

4 Stoeckel H, Hengstmann JH, Schuttler J. Pharmocokinetics of fentanyl as a possible explanation for recurrence of respiratory depression. Br J Anaesth 1979; 51: 741-5.

5 Becker L, Panlson B, Miller R, et al. Biphasic respiratory depression after fentanyl-droperidol or fentanyl alone used to supplement nitrous oxide anesthesia. Anesthesiology 1976; 44: 291-6.

6 Menkhaus PG, Reves JG, Kissin I, et al. Cardiovascular effects of esmolol in anesthetized humans. Anesth Analg 1985; 64: 327-34.

7 Jacque JJ, Gold MI, Grosnoff D, Whirley J, Herrington C. Does single bolus esmolol two minutes before intubation prevent tachycardia? Anesth Analg 1989; 68: S321.

8 Ebert TJ, Bernstein JS, Stowe DF, Roerig D, Kampine JP. Attenuation of hemodynamic responses to rapid sequence induction and intubation in healthy patients with a single bolus of esmolol. Journal of Clinical Anesthesia 1990; 2: 243-52.

9 Oxon D, Knox JWD, Hill J. Bolus doses of esmolol for 
the prevention of perioperative hypertension and tachycardia.

Can J Anaesth 1990; 37: 260-9.

10 Miller DR, Martineau RJ. Esmolol for control of haemodynamic responses during anaesthetic induction. Can J Anaesth 1989; 36: S164-5.

11 Cole CP. Bolus esmolol and the postintubation response in patients induced with fentanyl/thiopental. Anesth Analg 1990; 70: S65.

12 Chung KS, Sinatra RS, Chung JH. The effect of intermediate dose labetalol on heart rate and blood pressure responses to laryngoscopy and intubation. Journal of Clinical Anesthesia 1992; 4: 11-5.

$13 \mathrm{McClain}$ DA, Hug CC Jr. Intravenous fentanyl kinetics. Clin Pharmacol Ther 1980; 28: 106-14.

14 Reitan JA, Stengert KB, Wymore $M L$, et al. Central vagal control of fentanyl-induced bradycardia during halothane anesthesia. Anesth Analg 1978; 57: 31-6.

15 Miller DR, Martineau RJ, Wyands JE, Hill J. Bolus administration of esmolol for controlling the haemodynamic response to tracheal intubation: the Canadian multicentre trial. Can J Anaesth 1991; 38: 849-58. 